\title{
Selected solutions for rehabilitation of wooden structures: some Portuguese case studies
}

\author{
Artur O. Feio ${ }^{1, a}$, Daniel Félix ${ }^{2, b}$, Vítor M. Cunha ${ }^{3, c}$ and José S. Machado ${ }^{4, d}$ \\ ${ }^{1}$ University Lusíada of Vila Nova de Famalicão, V. N. Famalicão, Portugal \\ ${ }^{2}$ University Lusíada of Vila Nova de Famalicão, V. N. Famalicão, Portugal \\ ${ }^{3}$ University of Trás-os-Montes e Alto Douro, Vila Real, Portugal \\ ${ }^{4}$ LNEC, Lisboa, Portugal \\ aartur.feio@fam.ulusiada.pt, ${ }^{b}$ ffelixdaniel@gmail.com, ${ }^{c}$ vcunha@utad.pt, ${ }^{d}$ saporiti@lnec.pt
}

Keywords: Wood Architecture, Wood Structures, Rehabilitation, Structural Analysis, Retrofitting.

\begin{abstract}
Timber is one of the most used materials in the roofs and floors of monumental constructions in Portugal. The geometry is defined by elements that occupy a limited and well defined part of the tri-dimensional space, with a clear evidence of the hierarchy of the components. Timber elements are often visible, which allows easier conservation, identification of the wood species, characterization of details and evaluation of deterioration.

Complex timber structures, such as those belonging to the roofs of large monuments, are often not easy to understand in a expedite way. As the coverings of monuments as cathedrals, public buildings, mansions or villas show very complicate features, not easy to be understood during the first inspection. This is not only due to the fact that the system is very elaborate and to the large number of members but also due to continuous changes and repair past works, mostly with additional stiffening or propping. The typical result of the history of the construction is the increase in the number and the heterogeneity of the members, together with a multiplicity of connections and diversity of supports. This means that the original must be distinguished from the additions and the replacements. This complexity makes the field of conservation of historical timber structures not only a challenge but a field much in need of modern research.

The objective of this paper is to present some of the Portuguese experience in this field, showing how the rehabilitation solutions can be supported by the inspection techniques and by an extensive knowledge about the constituent material from which the structure was made, both from the mechanical point of view and from the physical point of view. A number of case studies will be presented to illustrate common conservation problems, and design problems as well as the possibilities and limitations of several solutions and to discuss the suitability of several intervention methods.
\end{abstract}

\section{Introduction}

Timber, frequently associated with masonry and stone, is the material most uninterruptedly used by mankind. Thus, the heritage of timber structures is immense and several and wideranging structural typologies and functions are assigned to these structures.

Timber is also one of the most used materials in specific typologies of roofs and floors (housing, churches, public building, schools, etc.) in Portugal, Fig. 1. Complex timber structures, such as those belonging to the roofs of large wood structures, are often not easy to understand in a expedite way. This complexity makes the field of wood structures not only a challenge but a field much in need of modern research. 


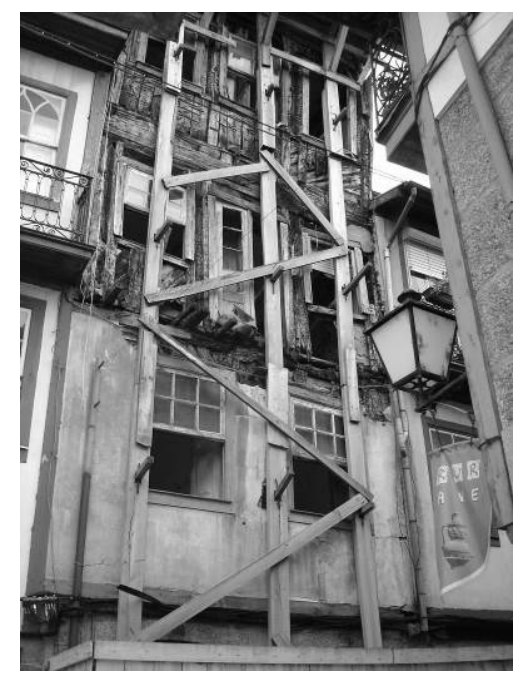

Figure 1. Rehabilitation in the historic Centre of Guimarães: UNESCO World Heritage Centre and European Capital of culture 2012.

In the past, timber structural design was dominated by the carpenter know-how which in turn was based upon his previous works or upon the works of others both supported on timber trusses solutions that performed reasonable well (did not fall). Although carpenters awareness that some members were subjected to tension and others to compression stresses is evident from the observation of old timber structures, the lack of scientific understanding about the global structural behaviour of timber trusses led sometimes to structural anarchy which is also perceptible on joints. From an engineering point of view one of the most important questions is that structures are usually designed to respect simple execution, economy, adequate structural behaviour and safety of the occupants.

In traditional timber constructions load distribution through joints was made with empirical knowledge, transmitted and improved through generations. The early design rules or standards were built upon this empirical evidence. The geometric configuration of old timber joints varies, depending on the structural elements connected and on the skills of ancient builders.

This paper presents some of the Portuguese experience in this field, showing how architectural solutions can be supported by an extensive knowledge about the constituent material from which the structure was made, both from the mechanical point of view and from the physical point of view. A number of case studies will be presented to illustrate common design problems and solutions, as well as the possibilities and limitations of this material.

\section{Case Studies}

Churches: Salesiano's Church - Estoril, Portugal. The origin of the Salesianos's Church dates back to the middle of the 20th century (1948). The original structure of the roof was entirely made of timber, see Fig. 2a, and the owner did not want to keep the existing roof structure due to the fact that: (i) previous remedial measures did not provide a real solution, (ii) a change in the interior of the choir was needed taking into account that the choir-organ did not performed well because of the proximity to the ceiling, see Fig. $2 b$. The demand of the owner organist was the real spark to the intervention.

The exiting timber structure is composed by pine, exact specie unknown, trusses and has a span around $13.5 \mathrm{~m}$ being composed by: (i) a set of main trusses, spaced $4.20 \mathrm{~m}$; (ii) secondary trusses located only in the area closer to the vault in the altar which does not allow a traditional roof structure using a tie beam. 


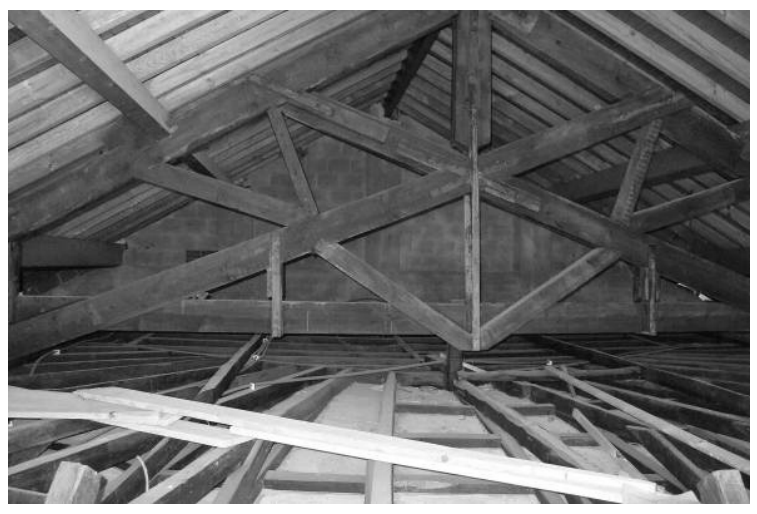

(a)

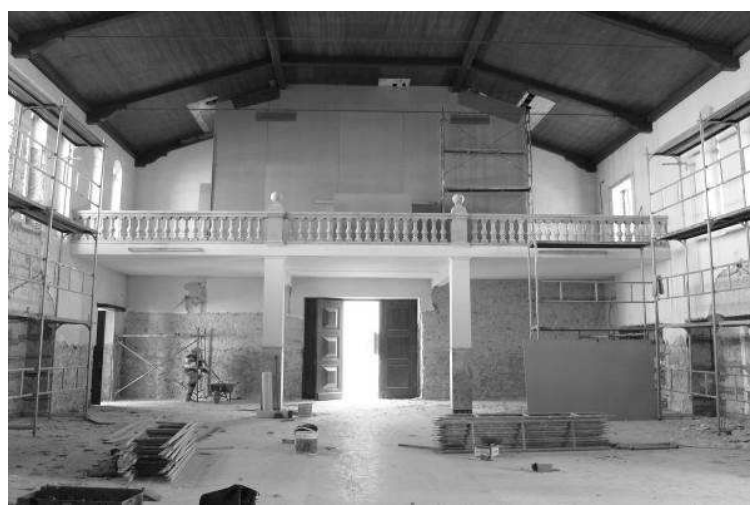

(b)

Figure 2. Salesiano's Church: (a) view of the roof structure (example of the existing main trusses), and (b) localization of the choir-organ and its proximity to the ceiling.

The structure was initially visually inspected and it was possible to verify that the timber is globally in good condition and exhibits no structural damage; however treatment against xylophagous insects was needed. In this case, no NDT or SDT in situ tests were performed.

A solution has been proposed: to adopt a new timber solution using new curved elements/trusses, see Fig. 3a to Fig. 3f, supported in a ring concrete beam that will be constructed on the side masonry walls. The timber structure was of glulam conifer wood (GL 28h, according EN 1194) elements ranging about $7.0 \mathrm{~m}$ long and 190/670 $\mathrm{mm}$ cross-section.

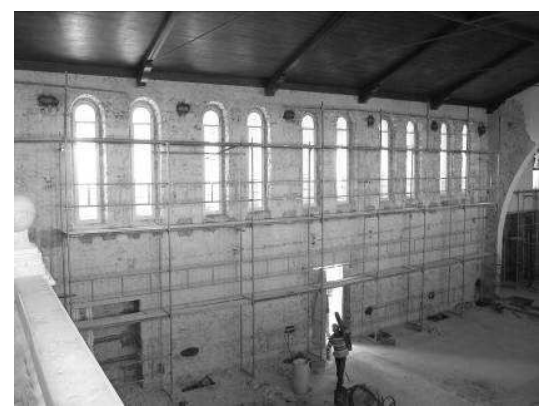

(a)

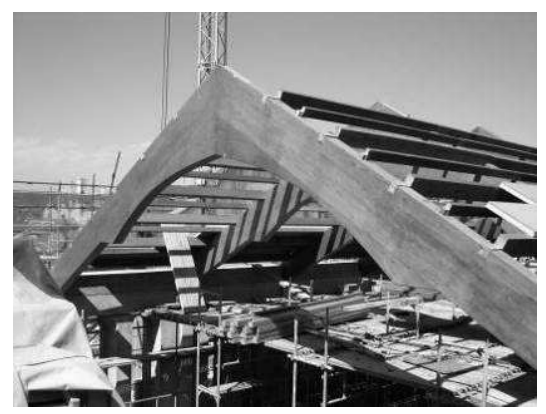

(d)



(b)

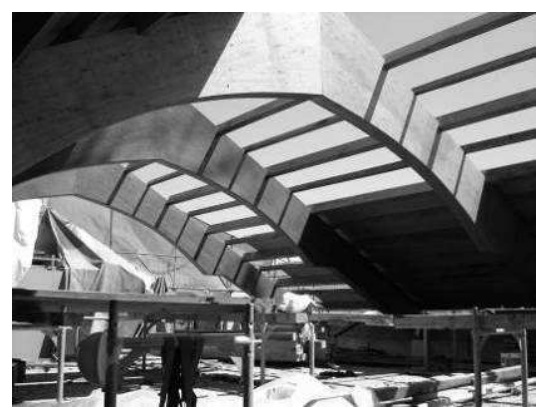

(e)



(c)

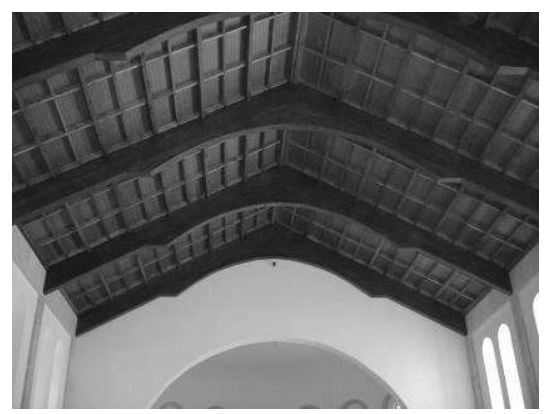

(f)

Figure 3. Salesiano's Church: (a) to (f) different perspectives, details and phases of the construction process of the new roof structure.

The top ridge tiles are to be placed dry, in order to allow ventilation. The airflow is to be ensured by small plastic tubes located in the bottom part of the roof. All the joint connections (nails, bolts and plates) are made with steel cross connectors (AISI 316). The upper and bottom steel crosses are 
connected with M-14 presstresed bolts to each timber element in the joint. Loadings were taken according to Eurocodes. The construction of the roof structure, including the roofing was completely produced and erected in 2,5 month time. The global timber volume, including the timber rafters and the main wood frames, is about $160 \mathrm{~m}^{3}$.

Santa Cruz Monastery's Reliquary Room - Coimbra, Portugal. The Santa Cruz Monastery is a National Monument in Coimbra, Portugal. Founded in 1131 outside the protecting walls of Coimbra, the Santa Cruz Monastery was the most important monastic house during the first times of the Portuguese monarchy.

The reliquary room exhibits considerable deformation and cracking of a timber vault, due to deformation of the roof above it, see Fig. 4a. The ground plan dimensions of the room are $12.5 \times 15$ $\mathrm{m}^{2}$, with a four-sloping roof with clay tiles and a timber lathwork vault rendered with stucco. It was carried out a visual inspection of each element within the structure, including a detailed description of the type, location and extent of defects and alterations, species identification, geometrical dimensions and joints evaluation. Also a more detailed timber analysis, by means of appropriate in situ application of semi and non-destructive techniques, in order to provide qualitative data about some properties and biological damages, especially those located in the inner and hidden parts of the structure. It included moisture content, drill resistance (Resistograph) and Pilodyn measurements. Finally, the safety assessment of the structure and design of the rehabilitation/reinforcement plan was performed on the basis of the collected data.

The main timber structure is extremely complex and was exposed during its life to several degradation factors leading, in the absence of appropriate maintenance interventions, to the loss of its structural integrity, see Fig. $4 \mathrm{~b}$ to Fig. 4d. Additional supports were successively introduced to the roof (mainly timber struts) during its life, to face the excessive deformations, which loaded, and therefore cracked and damaged the lathwork vault, resulting also in several structural modifications of the original roof system, see Fig. 4e and Fig. 4f.

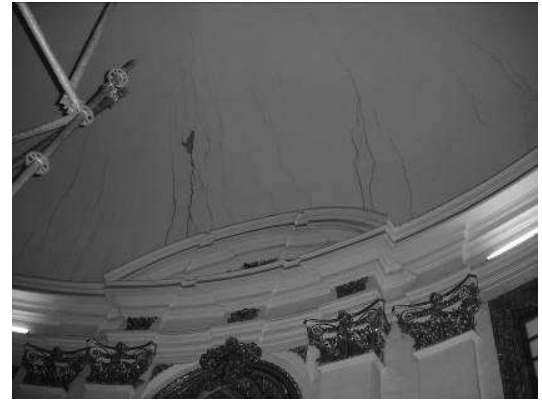

(a)

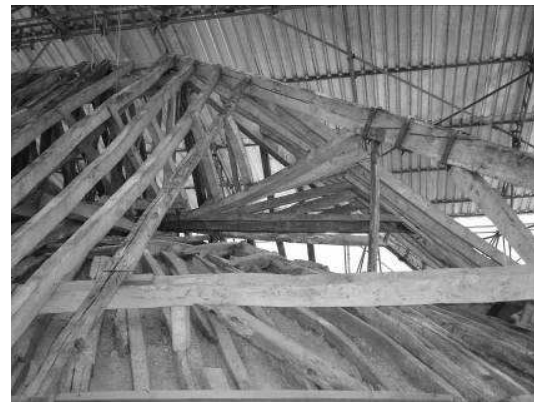

(d)



(b)



(e)

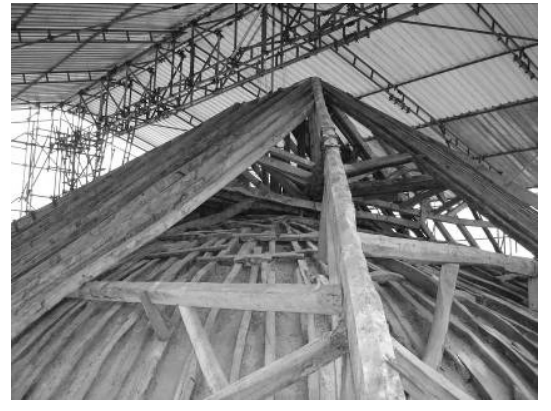

(c)

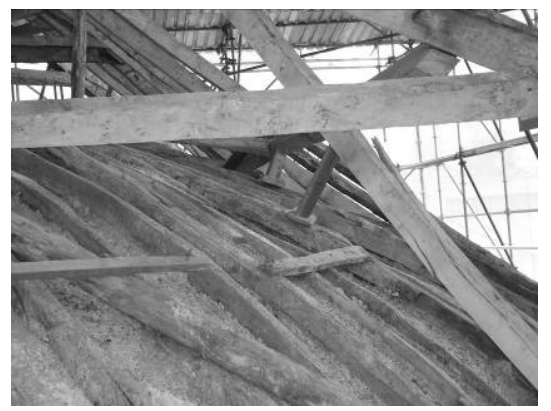

(f)

Figure 4. Santa Cruz Monastery - existing wood structure: (a) cracking of the stucco due to the deformation of the timber lathwork vault, (b) to (d) details of the complex existing structure, (e) and (f) additional supports introduced. 
Due to a poor design, some timber elements became loose/sloppy and some joints suffered premature failure due to large displacements. Damage includes humidity stains and rotten roof sheating (it was estimated that $30 \%$ of the sheating needed replacing). Also, most timber elements presented medium to severe decay, usually limited to the sapwood, while some elements presented also mechanical failure. The semi and non-destructive tests' results confirm that only the sapwood of the structural elements is attacked and the sheathing boards are usually strongly deteriorated.

Due to the generally poor state of the main roof structure, and taking into account that the structural safety and timber conservation requirements were not satisfied, two alternative solutions have been proposed to the owner: (i) keep the existing timber structure using new curved elements supported on the side walls; (ii) adopt a new timber structure. The owner decided to proceed to the integral replacement of the roof structure restoring and preserving some of the original members and their functionality, see Fig. 5. The timber used was pine (Pinus Pinaster Ait.).

The presence of the inner vault does not allow a traditional roof structure using a tie beam. Therefore, the solution includes four diagonal rafters and a ridge board, together with a set of purlins at mid-height of the rafters, two central trusses and four corner trusses (reducing the span of the main trusses), see Fig. 5a. The supports of the diagonal rafters and the side trusses will be made in existing recesses in the ring concrete beam introduced at the top of the masonry walls to hold them together, see Fig. 5d.

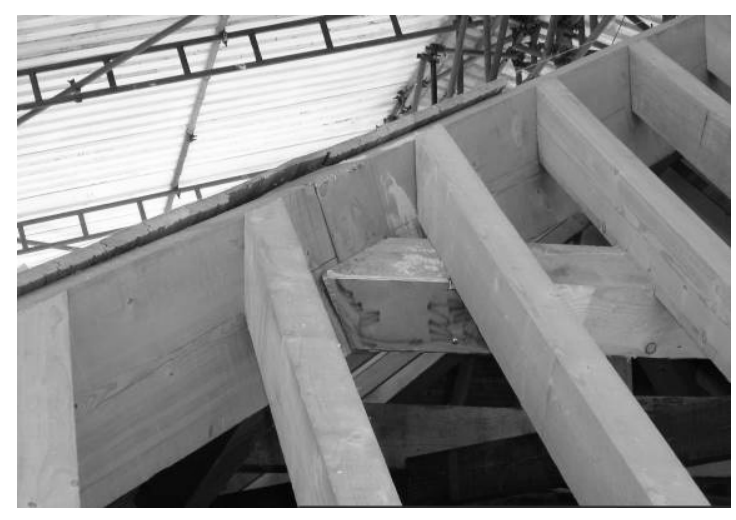

(a)

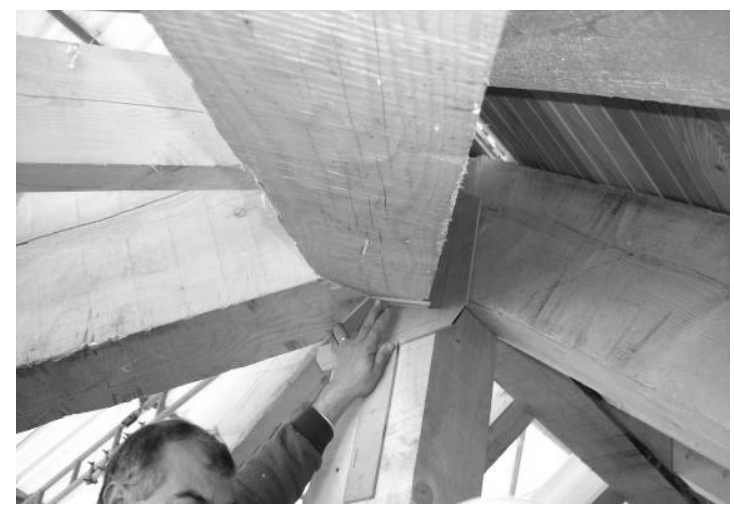

(c)



(b)

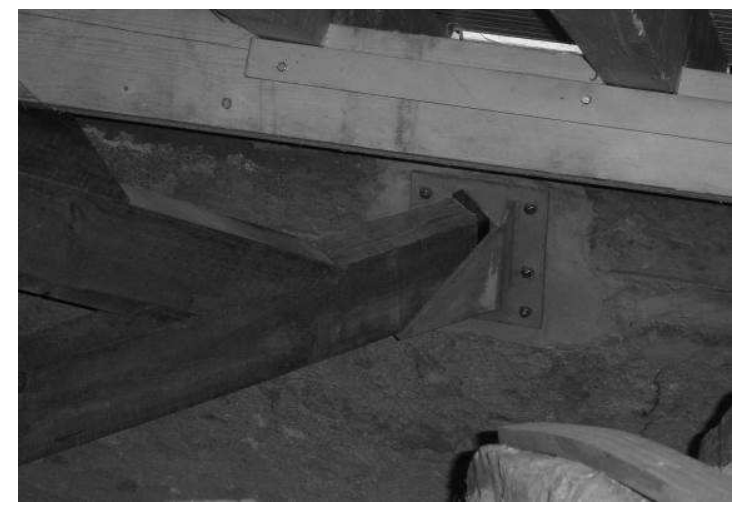

(d)

Figure 5. Santa Cruz Monastery: (a) to (d) view and details of the new roof structure and existing vault. 
Historical Neighbourhoods: Housing in Lapa and Graça - Lisbon, Portugal. Lisbon is one of the oldest cities in the world and a mosaic of picturesque neighbourhoods. It has strong links to the past, reflected in the old buildings and narrow cobblestone streets.

The quarter Lapa was formed on 1770. The development of this historic quarter took place after the earthquake of 1755, under the urban trace and orientation of Pombaline buildings. Lapa is mainly a residential area and also a large presence in trade and services, where you can find the oldest bandstand built in Lisbon. Up on the hill is the residential Graça district, a splendid viewpoint offering a panoramic view of the castle and central Lisbon. This is the highest point in the city and is known for its tranquil vibe, thanks to its peaceful views.

In these historical neighbourhoods the interventions are mainly in floors, stairs and roofs structures. Floors (and stairs) were frequently made by a system of beams up to 6-7 $\mathrm{m}$ of length spaced around $400 \mathrm{~mm}$ up to $600 \mathrm{~mm}$. The presented cases, see Fig. 6, are a good example of this situation. Because of the bad general state of the timber due to a long abandon period of some of these houses, the common solution adopted is the global substitution of the timber elements, but following the same structural solutions.

Fig. 6a to 6c present a Lapas' house ceiling rehabilitation with the partial substitution (80\%) of the timber elements with CCA vacuum treated pine timber (Pinus pinaster Ait.). The visual inspections allowed to maintain some of the original elements, see Fig. 6c., and no other NDT or SDT in situ tests were performed.

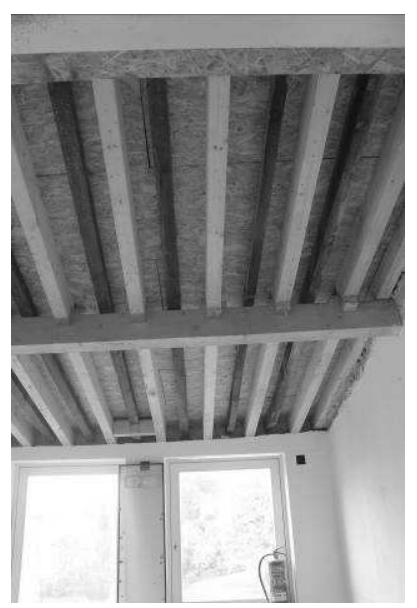

(a)



(d)


(c)

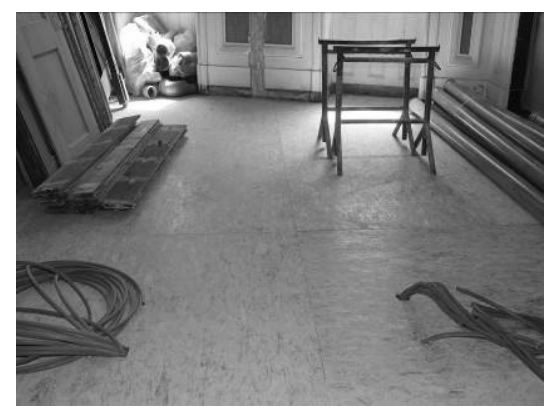

(f)

Figure 6. Lisbon historical neighbourhoods housing: (a) to (c) Lapas' house ceiling rehabilitation, and (d) to (f) Graças' house floor reinforcement. 
In 6d to 6f a Graças' house floor reinforcement is presented. In this case the original timber structure of the floor was replaced by a metallic solution/frame (due to architectural reasons related with the fact that the house will be used as a restaurant, see Fig. 6e) combined with timber elements with CCA vacuum treated pine timber (Pinus pinaster Ait.) and OSB panels. The traditional usage of wood in Portugal takes into consideration the local predominance of species but also its structural or ornamental function. However, in the North of Portugal the use of oak and chestnut is predominant in most buildings. In the rest of the country the use of pine predominates.

The relevance of carpenters was clearly stressed during the period of the reconstruction of downtown Lisbon, after the disastrous 1755 earthquake. The new constructions were based on a composite wooden structure of plummets, crosspieces and diagonal lines, filled by masonry, constituting a three-dimensional frame of very high ductility and with an excellent anti-seismic behaviour, see Fig. 7. This, so-called "Pombaline" system, represents a genuine Portuguese structural typology especially conceived to enhance the seismic performance and following the experience in timber construction. Here "Pombaline" is the term coined after the Marquis of Pombal, the prime minister at the time of the 1755 earthquake, who took most of the decisions regarding the reconstruction of Lisbon.

Here, it is possible to observe, see Fig. 7d to 7f, a reconstruction of some of these "Pombaline" frames using CCA vacuum treated pine timber (Pinus pinaster Ait.) following the pre-existent structural solutions.

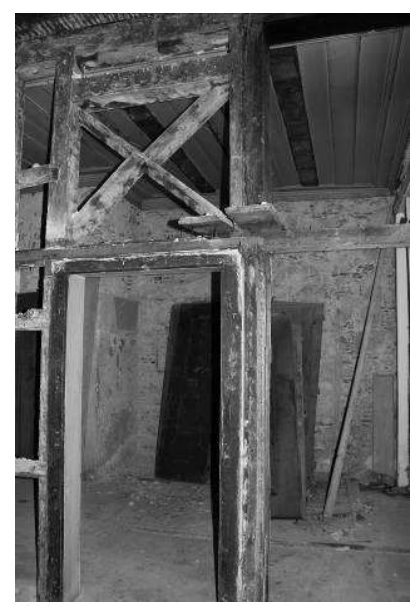

(a)

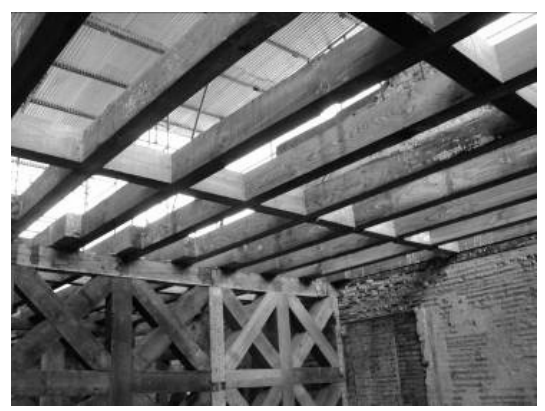

(d)

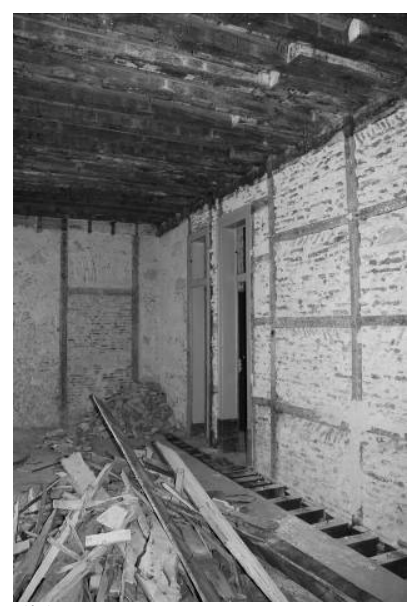

(b)



(e)

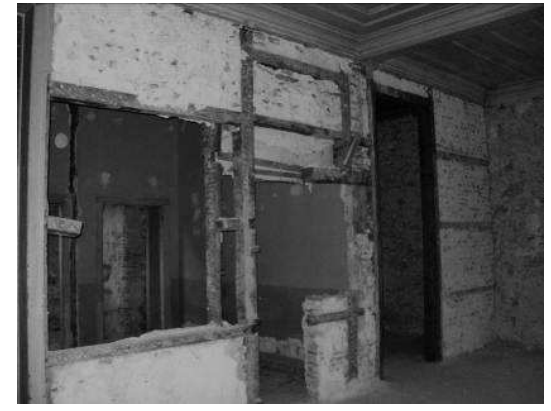

(c)

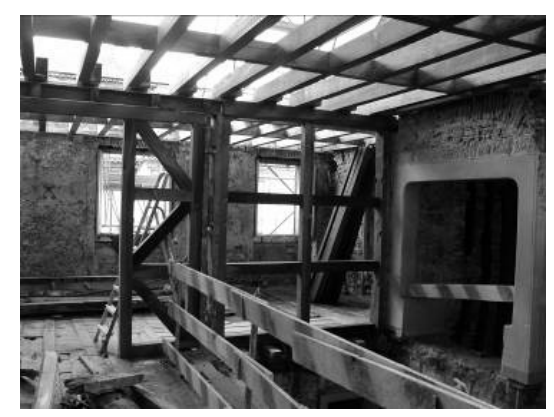

(f)

Figure 7. Downtown Lisbon (Baixa Pombalina): (a) to (f) different perspectives and details of an intervention in a "Pombaline" system building. 


\section{Summary}

A series of case studies depicting the value and importance of timber construction have been presented to showcase wooden structures intervention cases in Portugal. The combination of knowledge, architecture and structural analysis are key factors to a successful approach.

The case studies presented highlight the Portuguese experience in this field, showing the strategy of intervention adopted, due to factors other than those related to the quality or the conservation state of timber structures, highlighting the opportunities available to owners, in exploiting options for re-use and rehabilitation of wood structures.

\section{References}

[1] V. Cóias e Silva, P. B. Lourenço, L. Ramos, C. Mesquita, Accounting for the "block effect" in structural interventions in Lisbon's old "Pombaline" downtown buildings, Historical Constructions, P. B. Lourenço, P. Roca (Eds.), Guimarães: pp. 943-952, 2001.

[2] A. Feio, Inspection and Diagnosis of Historical Timber Structures: NDT Correlations and Structural Behaviour, PhD thesis, University of Minho, 2006.

[3] A. Feio, P. B. Lourenço, Reinforcement Design of the Roof of the Reliquary Room in Santa Cruz Monastery‘s, Coimbra, Report 03-DEC/E-14, University of Minho, 2003.

[4] P. B. Lourenço, A. Feio, R. Brites, Roof of the Reliquary Room in Santa Cruz Monastery‘s. Notes about the intervention, Construction Magazine $\mathrm{n}^{\circ} 20$ - Wood Construction, pp. 40-44, ISSN 1645-1767.20, 2007.

[5] CEN; 2002 - "EN 1194: Timber structures. Glued laminated timber. Strength classes and determination of characteristic values". Office for Official Publications of the European Communities. Brussels, Belgium. 